\title{
KARAKTER ANIMASI UNTUK INTELLECTUAL PROPERTY BERBASIS EKSPLORASI VISUAL MUSIK DANGDUT
}

\author{
Brenda Christanto ${ }^{1)}$, Arik Kurnianto ${ }^{2)}$ \\ School of Design, Universitas Bina Nusantara \\ Jl. K. H. Syahdan No. 9, Kemanggisan, Palmerah, Jakarta 11480, Indonesia \\ Ibrenda.christanto@binus.ac.id, ${ }^{2}$ arikkurnia@binus.ac.id
}

\begin{abstract}
Abstrak
Dangdut adalah genre musik tradisional populer dari Indonesia yang berakar pada musik-musik Malaysia, Hindustani, dan Arab. Unsur Arab pada musik ini muncul dari pedagang-pedagang yang berasal dari Gujarat bersamaan dengan penyebaran agama Islam. Selain mereka, musikmusik India juga menjadi pengaruh besar yang digunakan pada film-film Bollywood. Sejarah musik dangdut dimulai pada tahun 1968. Genre musik ini sangat populer karena vokal dan instrumennya yang melodis, terutama tabla. Namun, masyarakat ada yang belum suka musik dangdut. Terutama para generasi muda dari umur 18 sampai 25 yang lebih menyukai musik barat yang bergenre pop atau electronic. Dengan adanya Intellectual Property (IP) untuk musik dangdut, masyarakat mau mencoba mendengar musik dangdut. Dari masalah tersebut, tujuan dari perancangan visual ini adalah untuk memancing warga Indonesia supaya lebih sering mendengar musik dangdut. Untuk menghasilkan desain yang disukai orang-orang, maka dibutuhkan penelitian secara metode kualitatif dan kuantitatif dalam hal desain, pendapat tentang musik dangdut dan barang yang digunakan sehari-hari. Hasil dari riset ini adalah IP dengan desain berdasarkan musik dangdut yang disukai orang-orang untuk animasi serial.
\end{abstract}

Kata Kunci: Dangdut, musik, visual, Intellectual Property, generasi muda

\begin{abstract}
Dangdut is a popular traditional music genre from Indonesia that started from Malaysian, Hindustan, and Arab music. Arab element on this genre appeared from merchants from Gujarat along with transmission of Muslim religion. Aside from them, Indian music was also a big influence that is used on Bollywood films. History of Dangdut music started in 1948. This music genre was so popular because of the melodic vocal and instruments, especially tabla. Unfortunately, there was still people who doesn't like Dangdut. Mainly on young generation from age 18 to 25 who likes Western music with pop or electronic genre. With Intellectual Property (IP) for Dangdut, people will try to hear Dangdut. From that problem, the goal from this visual design is to bait Indonesian to hear Dangdut more. To produce likeable design, research with qualitative and quantitative methods are needed for design, opinions about Dangdut, and everyday items. Result from this research is IP with Dangdut design for serial animation.
\end{abstract}

Keywords: Dangdut, music, visual, Intellectual Property, young generation

\section{PENDAHULUAN}

$I P$, or "intellectual property" is the cornerstone of the protection of creativity ("Design Council", 2017), yang berarti Intellectual Property (IP) adalah landasan awal untuk melindungi kreativitas. Semuanya diawali dengan idea yang baik, tapi harus dipastikan orang lain tidak bisa mengambil 
atau meniru apa yang sudah dibuat saat diperkenalkan ke publik. Ada banyak tipe-tipe perlindungan untuk barang yang berbeda-beda; dari desain produk dan hak cipta karya seni, literatur dan musik, sampai merk dagang dan hak paten untuk ciptaan.

Contoh IP yang terkenal di Indonesia adalah Juki, karakter yang ada di dalam komik Si Juki. Karakter Juki diciptakan pada tahun 2010 saat pembuatnya yang disebut Faza Meonk untuk disebarluaskan kepada teman-temannya dalam bentuk komik. Setelah itu, komiknya disebarluaskan di sosial media seperti blog, KasKus, atau Facebook. Dikarenakan internet, karakter Juki menjadi terkenal, dikenal dengan keunikannya dari mata, hidung, dan giginya.

Dangdut sendiri menjadi hal yang menarik dikarenakan musik dangdut selalu mengikuti zaman. Pasalnya, Dangdut selalu mencerminkan kebaruan yang ada di eranya (Raditya, 2017). Lirik lagu yang ada juga simpel dan mudah dimengerti, tidak menggunakan kata-kata puitis seperti lagu Indonesia lainnya. Oleh karena dua hal tersebut, lagu dangdut bisa tersebar luas dengan mudah karena selain mengikuti zaman, lagunya juga mudah dimengerti masyarakat. Seperti contoh, pada tanggal 17 November 2017, masyarakat heboh dengan berita tiang listrik yang ditabrak oleh salah satu politikus Indonesia, Setya Novanto. Mobil Fortuner yang membawa Setya Novanto menabrak salah satu tiang listrik di Jalan Permata Berlian, Kawasan Permata Hijau, Jakarta Selatan (Rachman, 2017). Pada tanggal 27 November 2017, penyanyi dangdut Selvi Kitty melirik lagu barunya yang berjudul "Cintaku Sekuat Tiang Listrik" di YouTube.

Namun, target penulis yaitu generasi muda berumur 18 sampai dengan 25 tahun, lebih menyukai musik barat, terbukti dari artikel yang tertulis di tirto.id. Tertulis bahwa hasil wawancara Ypulse.com, 90 persen dari usia 13 - 33 tahun menyukai 17 musisi atau band antara lain: Taylor Swift, Beyonce, Adele, Twenty One Pilots, Rihanna, Drake, Sia, Kanye West, Kendrick Lamar, Carrie Underwood, Justin Timberlake, Lin Manuel Miranda, Pink, Linkin Park, Katy Perry, Adam Levine, dan Coldplay (Alexander Haryanto, 2016).

Untuk penelitian ini, IP yang dibuat akan digunakan untuk animasi serial. Membuat karakter untuk dijadikan IP bisa dianggap sebagai Core dalam bisnis. The Core is something that allows you to deliver the benefits your customers value with much greater effectiveness than any other competitor (Bill Aulet, 2013). Dalam konteks bisnis, Core adalah sesuatu yang dimiliki oleh pengusaha untuk memberikan keuntungan dengan nilai yang lebih efektif dari kompetitor lain, sesuatu yang membuat orang lain sangat sulit untuk ditiru oleh perusahaan lain yang ingin meniru. Dalam hal desain, Core berarti sebuah desain yang menjadi suatu keunikan tersendiri atau ciri khas dari desain itu. Dengan kata lain, karakter yang dibuat harus unik dan disukai oleh orang lain supaya bisa bersaing dengan karakter-karakter lain.

\section{METODE PENELITIAN}

Dalam penelitian ini, penulis akan menggunakan metode kualitatif dan kuantatif. Metode kuantitatif akan dilakukan dengan menyebarkan kuesioner secara online dan secara langsung menggunakan kertas. Penyebaran kuesioner menggunakan kertas akan dilanjutkan dengan penelitian metode kualitatif, yaitu menanyakan pendapat mereka terhadap musik dangdut maupun desain karakter. Dalam metode ini, penulis bisa menanyakan mengapa mereka memilih jawaban mereka dalam kuesioner.

\section{Wawancara}

Penulis juga akan melakukan wawancara kepada narasumber yang dapat dipercayai untuk mendapatkan informasi mengenai Dangdut maupun IP.

\section{Pengumpulan Data}

Data dikumpulkan dari kuisioner dan berinteraksi dengan responden mengenai musik dangdut. Dengan ini, penulis dapat mendapat data secara langsung dan tidak langsung, sesuai dengan metode yang dilakukan. Penulis juga akan membaca buku-buku tentang musik dangdut untuk mendapat pengetahuan lebih tentang musik dangdut. Pengetahuan tersebut akan menjadi data untuk pembuatan IP. 


\section{Metode Desain}

Untuk memproduksi penelitian ini, penulis menggunakan beberapa langkah disertai riset yang akan dijadikan IP.

\section{Desain Karakter}

Implementation sees design development and its final delivery to the client (Gavin \& Paul, 2011). Desain karakter akan disesuaikan dengan data yang terkumpul. Karakter akan didesain sesuai dengan apa yang disukai masyarakat. Untuk warna akan disesuaikan dengan bagaimana responden melihat musik dangdut tergantung dari cara pandang mereka terhadap musik dangdut. Desain karakter tidak hanya satu, namun akan dibuat sebanyak-banyaknya sesuai ide yang didapat penulis. Nanti akan diseleksi untuk mendapatkan desain yang menggambarkan musik dangdut.

\section{Implementasi}

Dalam bagian ini, penulis akan menunjukkan desainnya kepada orang lain. Dari sini, penulis bisa mengetahui kekurangan atau kelebihan dari desain yang sudah dibuat. Hal ini dibutuhkan untuk menghasilkan desain yang sesuai dengan selera masyarakat.

\section{HASIL DAN PEMBAHASAN}

Desain IP Dangdut akan digunakan untuk TV Animasi Serial dengan cerita sebagai berikut:

Musik Dangdut merupakan musik nasional Indonesia. Mas Rhama yang disebut sebagai Raja Dangdut telah berhasil menarik perhatian masyarakat, baik pecinta musik Dangdut maupun tidak, dengan lagu Dangdut ciptaannya. Namun, penyanyi musik Dangdut tidak hanya Mas Rhama seorang diri. Muncul penyanyi-penyanyi musik Dangdut lain yang ingin meraih gelar Raja Dangdut dan persaingan terjadi.

Untuk style, penulis menggunakan style "chibi". Chibi is Japanese slang for "small" or "short." It's usually applied to objects, animals, or people (ie. a short person or a small child) (Mami Suzuki, 2016). Chibi dalam bahasa Jepang berarti "kecil" atau "pendek". Chibi memberikan kesan yang positif, yaitu lucu atau imut. Style ini dipilih untuk menutupi kesan "norak" dan "aneh" dari Dangdut, sesuai dengan hasil kuesioner yang menyatakan bahwa target pasar tidak menyukai musik Dangdut atau malu mengakui menyukai musik Dangdut karena norak dan aneh.

Berikut ini adalah hasil dari riset mengenai musik Dangdut untuk dijadikan Intellectual Property animasi serial:

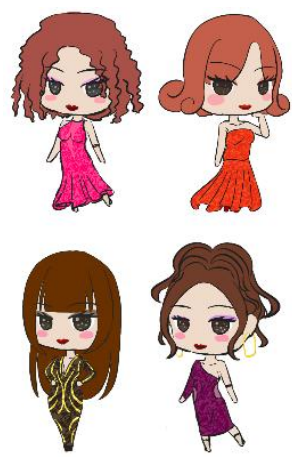

Gambar 1 Desain karakter Mbak Imul Sumber: Dokumen Pribadi

Mbak Imul adalah penyanyi Dangdut yang dikenal dengan goyangannya yang bernama "goyang ngedor" yang membuat Mbak Imul mendapat julukan "Ratu Goyang Ngedor". Mbak Imul sangat bergaya, bahkan tampilannya bisa sangat berbeda untuk setiap konser. Walaupun tampilannya berbeda, "goyang ngedor" khas Mbak Imul tetap sama. Karakter Mbak Imul didesain dengan menggunakan Inul Daratista sebagai referensi. 


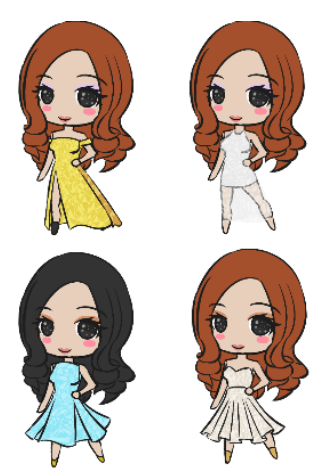

Gambar 2 Desain karakter Mbak Cyta

Sumber: Dokumen Pribadi

Mbak Cyta adalah penyanyi Dangdut Remix atau Dangdut Disco. Penampilan Mbak Cyta tidak banyak berubah, tetap tetap berkilau. Mbak Cyta mulai populer sejak merilis lagunya yang berjudul "Sakitnya Tuh di Ini", yang muncul pada saat hebohnya meme "sakitnya tuh di sini" di internet. Karakter Mbak Cyta didesain dengan menggunakan Cita Citata sebagai referensi.

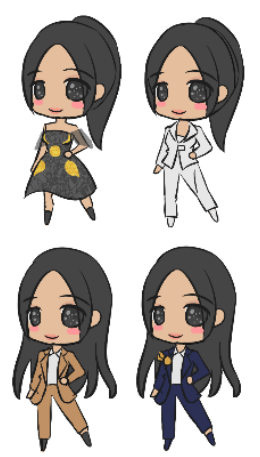

Gambar 3 Desain karakter Mbak Pia

Sumber: Dokumen Pribadi

Mbak Pia adalah penyanyi Dangdut Koplo yang berhasil mendapatkan julukan "Ratu Pop Koplo". Popularitas Mbak Pia melonjak berkat lagunya yang berjudul "Cayang". Mbak Pia juga menyanyikan theme song Asean Games 2018 yang berjudul "Meraih Banting". Mbak Pia selalu berpenampilan yang cukup sederhana, tidak seperti penyanyi Dangdut lainnya. Mbak Pia didesain dengan menggunakan Via Vallen sebagai referensi.

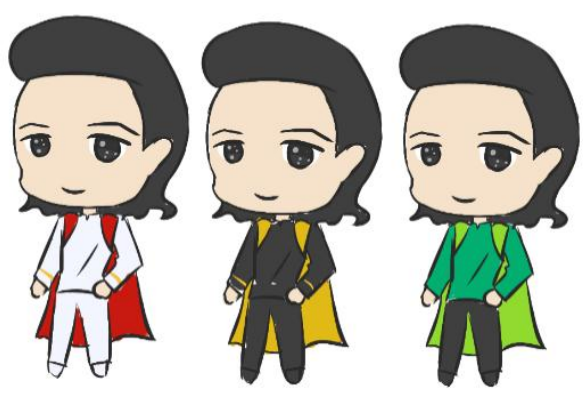

Gambar 4 Desain karakter Mas Rhama Sumber: Dokumen Pribadi

Mas Rhama adalah penyanyi Dangdut Melayu yang paling populer di Indonesia dan mendapatkan julukan "Raja Dangdut". Sebagai Raja Dangdut, Mas Rhama sangat menjaga image-nya. Mas Rhama selalu membawa gitar favoritnya saat mengadakan konser. Mas Rhama 
juga menegaskan bahwa Dangdut dan Koplo adalah dua hal yang berbeda, sehingga penjagaan image-nya gagal saat ada yang menyebut Dangdut Koplo. Mas Rhama didesain dengan menggunakan Rhoma Irama sebagai referensi.

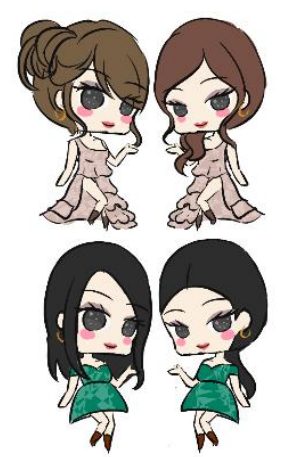

Gambar 5 Desain karakter Duo Anggur

Sumber: Dokumen Pribadi

Duo Anggur adalah penyanyi Dangdut duet. Sebelumnya, Duo Anggur memiliki goyangan khas yang bernama "Paha Mentok", tetapi Duo Anggur menjadi berbeda dengan pergantian salah satu personil Duo Anggur. Davey yang elegan dan Putri Imut dengan keunyuannya menjadi Duo yang kompak. Duo Anggur didesain dengan menggunakan Duo Anggrek sebagai referensi.

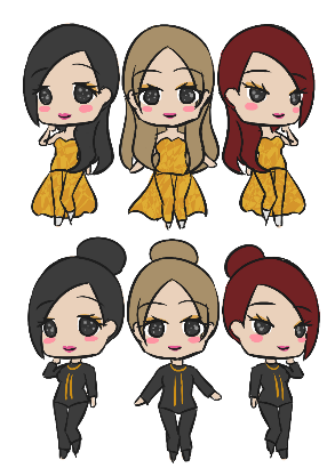

Gambar 6 Desain karakter Trio Singa

Sumber: Dokumen Pribadi

Trio Singa adalah grup trio Dangdut. Mereka sukses setelah merilis lagu yang berjudul "SNS", yaitu lagu yang menceritakan tentang fitur SMS yang ada di handphone yang masih sering digunakan sebelum munculnya smartphone. Sebagai trio, mereka selalu menggunakan pakaian yang serasi. Trio Singa didesain dengan menggunakan Trio Macan sebagai referensi.

\section{Konsep Desain}

Berikut ini adalah perancangan visual ekspresi karakter animasi untuk musik Dangdut. 


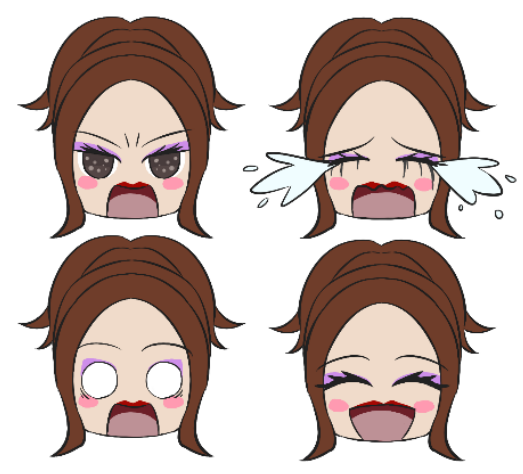

Gambar 7 Ekspresi Mbak Imul Sumber: Dokumen Pribadi

Mbak Imul digambarkan sebagai karakter yang sangat ekspresif, disesuaikan dengan pakaiannya yang sering sekali berubah-ubah. Oleh sebab itu, ekspresi Mbak Imul didesain berlebihan, seperti mulut yang terbuka lebar dan makeup yang sampai luntur saat menangis.
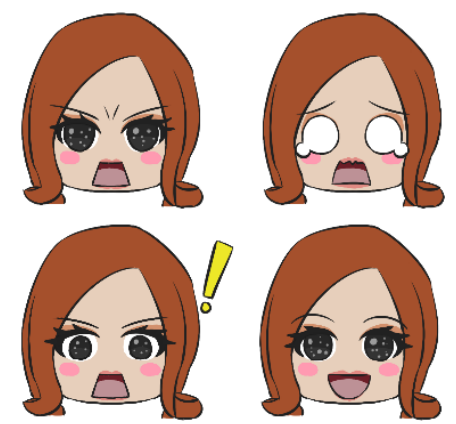

Gambar 8 Ekspresi Mbak Cyta Sumber: Dokumen Pribadi

Mbak Cyta digambarkan sebagai karakter yang cerita namun sebenarnya sedih di dalam, seperti yang digambarkan untuk ekspresi sedih yang berbeda dari yang lainnya. Karakter ini disesuaikan dengan lagu-lagu ciptaan Cita Citata yang memiliki lirik dengan unsur galau, namun musiknya menggunakan musik remix atau disco yang membuat lagu jadi tidak terdengar sedih.
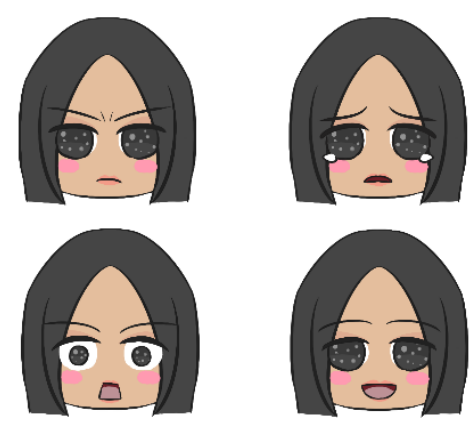

Gambar 9 Ekspresi Mbak Pia Sumber: Dokumen Pribadi 
Mbak Pia digambarkan sebagai karakter yang sederhana, disesuaikan dengan kesederhanaan dari Via Vallen. Oleh karena itu, ekspresi yang ditunjukkan tidak terlalu ekspresif, namun cukup simpel untuk menunjukkan perasaannya.
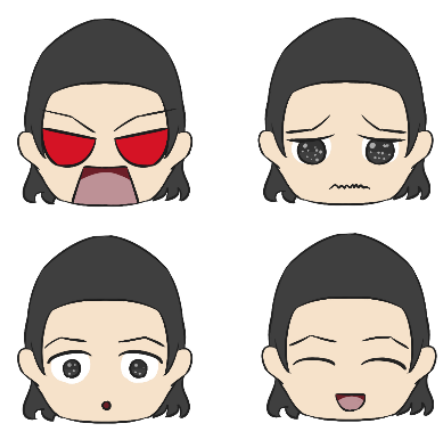

Gambar 10 Ekspresi Mas Rhama Sumber: Dokumen Pribadi

Mas Rhama digambarkan sebagai orang yang jaga image, tetapi ekspresinya ditunjukkan untuk bagian marah ketika ada yang menyamakan Dangdut dengan Koplo.
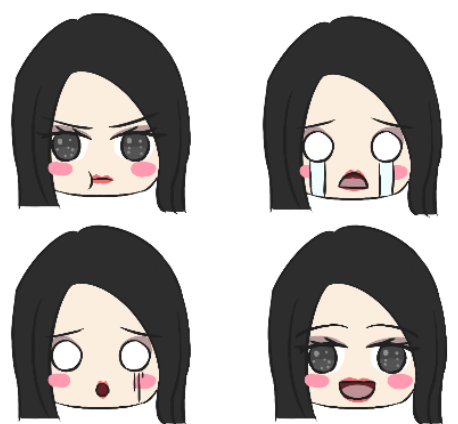

Gambar 11 Ekspresi Putri Imut Sumber: Dokumen Pribadi

Putri Imut digambarkan sebagai karakter yang imut dan unyu. Ekspresi yang ditunjukkan juga dibuat imut untuk menunjukkan keimutannya.

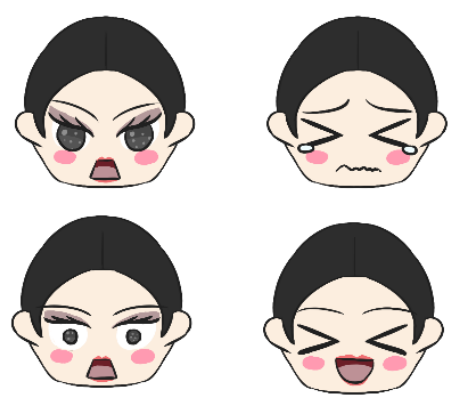

Gambar 12 Ekspresi Davey Sumber: Dokumen Pribadi 
Davey digambarkan sebagai karakter yang elegan karena merupakan personil awal dari Duo Anggur, namun dibuat imut untuk ekspresi sedih dan senang sesuai dengan cerita, yaitu perubahan yang terjadi setelah Putri Imut masuk ke dalam Duo Anggur.

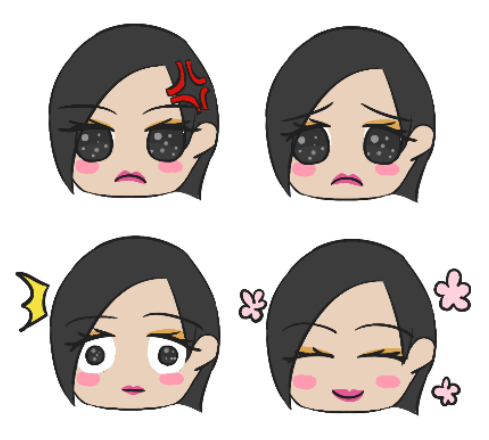

Gambar 13 Ekspresi Mbak Lea Sumber: Dokumen Pribadi

Mbak Lea digambarkan sebagai karakter yang pendiam. Oleh karena itu, ekspresinya ditunjukkan dengan mulut yang tertutup.
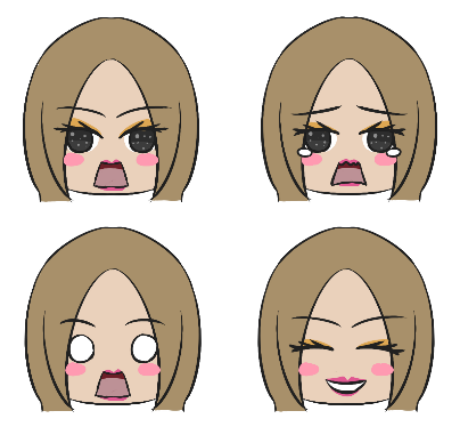

Gambar 14 Ekspresi Mbak Dora Sumber: Dokumen Pribadi

Mbak Dora digambarkan sebagai karakter yang ceria dan percaya diri. Untuk bagian senang, Mbak Dora digambarkan berani untuk menunjukkan giginya untuk menggambarkan kepercayaan diri.

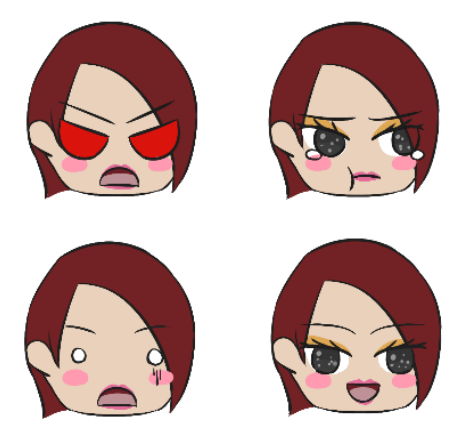

Gambar 15 Ekspresi Mbak Chichi Sumber: Dokumen Pribadi 
Mbak Chichi digambarkan sebagai karakter yang galak, digambarkan pada bagian sedih dengan alis yang menunjukkan sedikit rasa kesal.

\section{SIMPULAN}

Hasil riset menunjukkan bahwa generasi muda yang menyukai Dangdut ada yang malu karena takut dianggap norak dan aneh, dan yang tidak menyukai Dangdut tidak suka karena norak dan aneh. Penulis memilih style chibi untuk mendesain karakter agar karakter terlihat imut dan lucu untuk menutupi kesan norak dan aneh. Karakter didesain dengan menggunakan penyanyi Dangdut yang terkenal sebagai referensi, serta penyanyi-penyanyi Dangdut yang dapat mewakili satu genre tertentu. Pasalnya, Dangdut selalu mencerminkan kebaruan yang ada di eranya. Untuk riset ke depan, karakter dapat ditambahkan sesuai dengan perkembangan zaman.

\section{DAFTAR PUSTAKA}

Aulet, B. (2013). Disciplined entrepreneurship. John Wiley \& Sons, Inc., Hoboken, New Jersey.

Design Council. (2017). What is intellectual property - an expert's guide. Diakses dari https://www.designcouncil.org.uk/news-opinion/what-intellectualpropertyexpert-sguide

Haryanto, A. (2016). Memahami selera musik milenial. Diakses dari https://tirto.id/memahamiselera-musik-milenial-b49a

Rachman, F. F. (2017, 17 November). PLN kaget tiang listrik yang ditabrak Novanto masih berdiri tegak. Diakses dari https://finance.detik.com/energi/d-3731043/pln-kaget-tianglistrik-yang-ditabrak-novanto-masih-berdiri tegak?utm_medium=cpc\&utm_campaign= detikcomsocmed\&utm_source=facebook\&utm_content=pe\&utm_term=detikfinance

Raditya, M. H. B. (2017). Sejatinya, nasib dangdut di tangan anak muda. Diakses dari https://jurnalruang.com/read/1506940530-sejatinya-nasib-dangdut-di-tangan-anak muda?section $=$ Recent $\% 20$ Article \&position=3

Suzuki, M. (2016). Chibi: The Japanese word that's cute and offensive. Diakses dari https://www.tofugu.com/japanese/chibi/ 